\title{
A pesquisa como princípio pedagógico: Os desafios na práxis docente para ressignificação de conhecimentos
}

\section{La investigación como principio pedagógico: los desafios de la praxis docente para la resignificación del conocimiento.}

\author{
Marcia Isabel Gentil Diniz (marciagentil@uol.com.br) \\ Professora Adjunto IV na Universidade Federal Fluminense (UFF) \\ Leandro Alcasar Rodrigues (leandroalcasar@yahoo.com.br) \\ Faculdade de Educação São Luís \\ Rede Municipal de Jardinópolis-SP
}

Resumo: Quando se reflexiona sobre uma práxis educativa que atenda as demandas atuais faz-se evidente a falência da transmissão de conteúdos marcada historicamente pela abordagem tradicional. Nesse sentido surgem inquietações, pois o processo de ensino-aprendizagem demanda uma compreensão mais inovadora. A sociedade inaugura novos tempos que pedem novas formas de aquisição de conhecimentos que estabeleçam novas conexões. A relação ensino-aprendizagem se transformou, deixando no passado o retrato de um espaço arcaico tendo o mestre como protagonista cujas estratégias de ensino eram pautadas em aulas expositivas onde o aluno exercia um papel passivo. Hoje se preconiza uma concepção dialógica que concebe a educação como um ato político em transformação. Outro aspecto importante diz respeito à capacitação docente voltada para as Tecnologias de Informação e Comunicação (TIC). Trata-se de um estudo qualitativo de natureza bibliográfica, feito através de revisão narrativa. As discussões e resultados apontam que os professores precisam de suporte para superar suas dificuldades quanto ao uso de TIC; na conjuntura da globalização o professor necessita de capacitação para vislumbrar uma postura com cerne na pesquisa. Faz-se necessário ainda fortalecer políticas públicas de acesso ao mundo digital. A educação precisa se (re) inventar, visando uma sociedade com cidadãos críticos e autônomos.

Palavras-chave: Professor; Pesquisas; Tecnologia de informação e comunicação; Prática pedagógica.

Resumen: Cuando se reflexiona sobre una praxis educativa que responda a las demandas actuales queda evidente el fracaso de la transmisión de contenidos históricamente marcado por el estilo tradicional. Como consecuencia surgen preocupaciones, pues el proceso de enseñanza-aprendizaje demanda una comprensión más innovadora. La sociedad abre nuevos tiempos que exigen nuevas formas de adquirir conocimientos para crear nuevas conexiones. La relación enseñanza-aprendizaje se transformó, dejando en el pasado el retrato de un espacio arcaico con el maestro como protagonista, con estrategias didácticas basadas en clases expositivas donde el alumno desempeñaba un papel pasivo. Hoy se aboga por una concepción dialógica, que concibe la educación como un acto político en transformación. Otro aspecto importante es la formación del profesorado centrada en las Tecnologías de la Información y la Comunicación (TIC). Se trata de un estudio cualitativo bibliográfico, realizado mediante revisión narrativa. Las discusiones y resultados destacan que los docentes necesitan 
apoyo para superar sus dificultades en el uso de las TIC; en el contexto de la globalización se necesita preparación. También se hace necesario fortalecer las políticas públicas de acceso al mundo digital. La educación necesita (re) inventarse, teniendo como meta una sociedad con ciudadanos críticos y autónomos.

Palabras clave: Profesor; Investigación; Tecnología de información y comunicación; Práctica pedagógica.

\section{INTRODUÇÃO}

Ao se refletir sobre a historicidade e a complexidade do fenômeno educativo sob o ponto de vista da práxis docente, levando-se em consideração as transformações originárias da sociedade do conhecimento apontada em suas dimensões de transformação social, cultural, econômica, política e institucional com uma perspectiva mais pluralista e de desenvolvimento social, cabe destacar que, de acordo com Guichot Reina, (2006):

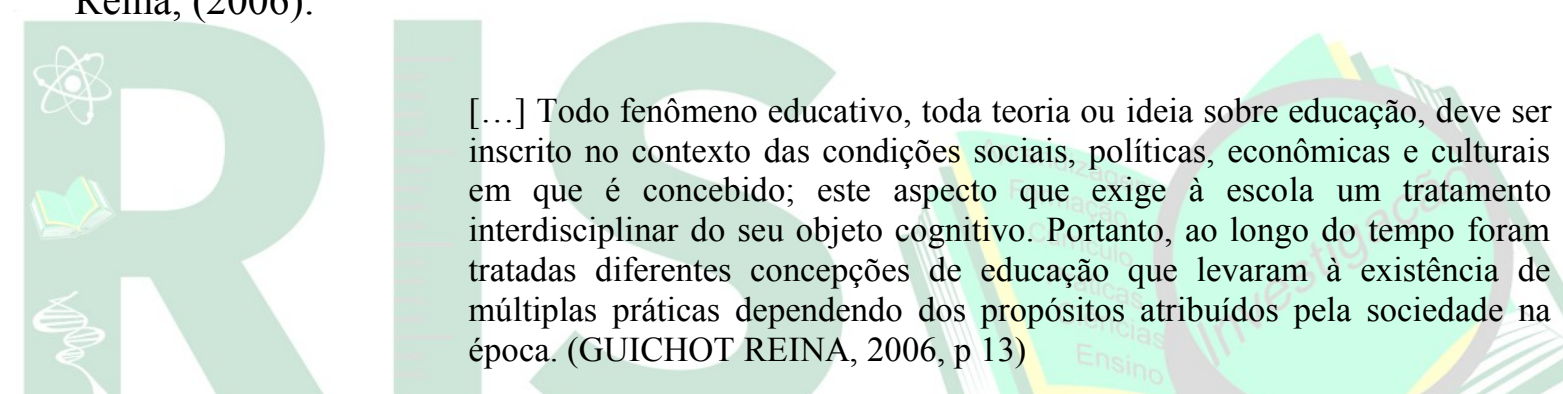

Contudo, embora esta necessidade urgente de transformação no processo ensinoaprendizagem venha sendo largamente difundida ao longo dos anos, percebe-se ainda que a grande maioria dos educadores, no cotidiano das escolas, prioriza métodos tradicionais em suas abordagens no processo ensino-aprendizagem.

Esta postura contraditória vem sendo largamente estudada pelos pesquisadores da área de educação, pois se trata de uma questão complexa em sua análise que evidencia visões de mundo multifacetadas. De acordo com Mizukami (1986), ao caracterizar a abordagem tradicional refere que:

[...] Nessa abordagem, quanto mais rígido o ambiente escolar, mais concentrado e voltado para a aprendizagem o aluno se mantinha. $\mathrm{O}$ professor era visto como mero repassador de conteúdo e o aluno como um ser passivo no processo. As habilidades desenvolvidas no aluno eram a memorização e a repetição (...). Daí vem à necessidade de o professor refletir sobre sua prática, mas é preciso compreender que isso será uma consequência do seu processo de formação continuada, no qual ele precisa se sentir envolvido. (MIZUKAMI, 1986) 
Em decorrência tem-se por um lado o mecanismo de escolaridade vivida que se remonta ao que já foi instituído e sedimentado e por outro o surgimento de sistemas educativos modernos com todos os seus desafios.

Os termos empregados pedagogicamente como "novo" e "tradicional" são utilizados para estabelecer padrões a dois conjuntos de ideias opostas, e se confrontam entre a pedagogia tradicional e a renovada, um embate entre o velho e o novo.

\section{Quadro 1 - Pedagogia tradicional VS. Pedagogia nova}

\begin{tabular}{|c|c|}
\hline ia "tradicional" & Peda \\
\hline programa e nas explicações do & resses dos alunos. \\
\hline m aluno nassivo recentor & $\mathrm{m}$ aluno ativo, construtor do \\
\hline Verl & $\begin{array}{l}\text { Dedicada a explorar diferentes linguagens y } \\
\text { modos de conhecer. }\end{array}$ \\
\hline Hier & fetivo, a imaginação. \\
\hline $\begin{array}{l}\text { istro, a memória, armazenamento de } \\
\text {, reprodução. }\end{array}$ & a \\
\hline $\begin{array}{l}\text { ta como uma condição } \\
\text { no. }\end{array}$ & com os alunos, \\
\hline $\begin{array}{l}\text { Há interesse em conseguir resultados } \\
\text { mensuráveis. }\end{array}$ & s processos. \\
\hline $\begin{array}{l}\text { O ensino responde a métodos que ditam uma } \\
\text { série de passos a serem seguidos, } \\
\text { preestabelecidos. }\end{array}$ & $\begin{array}{l}\text { tégica, } \\
\text { vel das }\end{array}$ \\
\hline $\mathrm{A} \mathrm{pl}$ & um ex \\
\hline $\begin{array}{l}\text { iação se materializa através de exames } \\
\text { s dispositivos experimentais destinados } \\
\text { ção. }\end{array}$ & $\begin{array}{l}\text { A avaliação se materializa através de } \\
\text { propostas dinâmicas, de produção aberta, } \\
\text { destinadas à reflexão sobre os processos de } \\
\text { aprendizagem. }\end{array}$ \\
\hline g) & $\begin{array}{l}\text { Os estudantes são percebidos com suas } \\
\text { particularidades. }\end{array}$ \\
\hline
\end{tabular}

Fonte: Brailovsky, 2018

De acordo com Brailovsky (2018), após uma análise comparativa, visualiza-se no quadro que:

"Há um universo nitidamente dividido por dois tipos de argumentos: de um lado o argumento conservador e do outro, progressista. O conservador, que remete ao hábito, ao consolidado, ao tédio e ao mecânico em contraposição da inovação, criatividade dos construtivistas". (BRAILOVSKY, 2018, p.163) 
Assim sendo, apresenta-se o mundo da pedagogia desconexo e bem estabelecido, o que implica um grande desafio para os docentes que tentam trabalhar com a "nova" pedagogia, aderindo da melhor forma possível aos princípios do lado direito da tabela.

Contudo, para isto acontecer o docente terá que superar, é claro, a "resistência as mudanças", os "hábitos profissionais" e outras adversidades que impedem a nova pedagogia de se manifestar em toda sua magnificência. Portanto, terá que, em sua práxis, implantar estas concepções em seu cotidiano docente.

Diante do exposto, depreende-se que uma vez internalizado tais apreensões implícitas nesta pedagogia denominada como "nova" o professor será reputado como moderno, atualizado e até inovador.

Quanto às abordagens ou modelos de ensino, ao se proceder também a uma análise mais criteriosa, temos do mesmo modo panoramas bem delineados e diversificados.

Quadro 2 - Modelo tradicional VS. Modelo tecnológico.

\begin{tabular}{|l|l|}
\hline Modelo tradicional ou clássico & Modelo tecnológico \\
\hline O professor como instrutor. & O professor como mediador. \\
\hline Coloca-se ênfase no ensino. & A ênfase é colocada na aprendizagem. \\
\hline $\begin{array}{l}\text { Professor isolado. } \\
\text { VISta InSionare Scien }\end{array}$ & $\begin{array}{l}\text { O professor colabora com a } \\
\text { equipe docente. }\end{array}$ \\
\hline $\begin{array}{l}\text { Geralmente aplica recursos sem } \\
\text { projetá-los. }\end{array}$ & $\begin{array}{l}\text { Projeta e gerencia seus próprios } \\
\text { recursos. }\end{array}$ \\
\hline $\begin{array}{l}\text { Didática expositiva e de caráter } \\
\text { unidirecional. }\end{array}$ & $\begin{array}{l}\text { Didática baseada em pesquisa e de caráter } \\
\text { bidirecional. }\end{array}$ \\
\hline $\begin{array}{l}\text { Só a verdade e o sucesso proporcionam } \\
\text { aprendizagem. }\end{array}$ & $\begin{array}{l}\text { Usa o erro como fonte de } \\
\text { aprendizagem. }\end{array}$ \\
\hline $\begin{array}{l}\text { Restringe a autonomia do } \\
\text { aluno. }\end{array}$ & $\begin{array}{l}\text { Promove a autonomia do } \\
\text { aluno. }\end{array}$ \\
\hline $\begin{array}{l}\text { O uso de novas tecnologias } \\
\text { está fora da programação }\end{array}$ & $\begin{array}{l}\text { O uso de novas tecnologias } \\
\text { está integrado no currículo. O } \\
\text { professor tem habilidades básicas em } \\
\text { TICs. }\end{array}$ \\
\hline
\end{tabular}

Fonte: Muñoz, 2003 
Ao se intentar refletir sobre a magnitude do papel docente no processo ensinoaprendizagem no qual ocorrem mudanças paradigmáticas invariáveis, fruto de uma sociedade em constante transformação e com uma imprecisa, porém rápida velocidade de demandas diversas relacionadas à aquisição de conhecimentos ressalta-se então Lima e Cosme (2018, p. 65-73) quando eles discutem o espaço da formação de professores como um período com intensa potencialidade para a transformação das práticas.

O espaço de primazia do ensino tradicional foi superado e não dá mais conta do processo educativo. Lima e Cosme (2018) assinalam que:

\begin{abstract}
"Visto que a formação de professores é complexa, moldada na confluência de experiências objetivas e percepções subjetivas acerca da profissão; é necessário resgatar as necessidades formativas, ou habilidades inerentes a uma prática pedagógica crítica e consciente. Mas não como receita, e sim como elemento de discussão e reflexão acerca dessa formação. Ensinar é uma prática cultural e alterar questões culturais não é um processo simples, nem tampouco fácil" (LIMA; COSME, 2018; p 70)
\end{abstract}

É possível então perceber que o professor não pode mais configurar-se apenas como um simples e ultrapassado "transmissor de conhecimentos" em uma sociedade que demanda constantes e rápidas inquietações. Na época presente percebe-se que, ainda de forma tímida, estão acontecendo mudanças paradigmáticas no ato educativo, pois do papel de protagonista na relação ensino-aprendizagem o educador necessita assumir o seu papel de coadjuvante e o único caminho a ser trilhado neste "novo" manuscrito educacional passa por uma práxis docente reflexiva com autoria de sua ação educativa e com uma postura investigativa.

Ainda nessa linha de raciocínio Freire (1999) afirma:

\begin{abstract}
"Não há ensino sem pesquisa e pesquisa sem ensino. Esses que fazeres se encontram um no corpo do outro. Enquanto ensino, continuo buscando, reprocurando. Ensino porque busco, porque indaguei, porque indago e me indago. Pesquiso para constatar, contatando intervenho, intervindo educo e me educo. Pesquiso para conhecer o que ainda não conheço e comunicar ou anunciar a novidade.” (FREIRE, 1999, p. 32).
\end{abstract}

Entretanto, para adotarem uma postura de professor/pesquisador faz-se imprescindível a reflexão do docente sobre a dimensão de sua práxis e as possibilidades que podem ser geradas em seu fazer docente elaborando pesquisas em educação.

Os professores precisam ser vistos e se assumirem como autores de sua prática e inquietações se tornando sujeitos investigadores capazes de meditar sobre seu contexto e investigar o mesmo sempre que julgarem necessário. 


\subsection{O PAPEL DO EDUCADOR NA SOCIEDADE DO CONHECIMENTO}

Atualmente se vivenciam tempos de profundas transformações na nossa sociedade, onde os desafios de ser educador passaram a ter uma complexidade crescente requerendo adequações incessantes a essa nova realidade, pois em panorama anterior o processo ensino-aprendizagem como sua atividade precípua não o desafiava, bastava ser um excelente conhecedor do conteúdo a ser ministrado aos seus passivos educandos.

Entretanto, tal panorama se modificou na atualidade levando o professor/ educador ir além da necessidade de apenas e tão somente transmitir conteúdos como na abordagem tradicional de ensino. No atual contexto, não existe uma única forma estabelecida, um padrão pré-determinado no processo ensino-aprendizagem. O êxito do educador moderno atuante está vinculado à sua personalidade, competência, facilidade de aproximar e trabalhar em equipes assim como gerenciar pessoas e situações cada vez mais diversificadas.

O significado mais profundo do termo sociedade do conhecimento é que se antes a cultura era ciência, hoje a ciência é a cultura dominante que afeta o que é integral para toda a humanidade. Assim, uma segunda característica dessa sociedade do conhecimento é que, para ser um sujeito eficiente e capacitado socialmente, é necessária uma crescente formação formal. As pessoas que não conseguem atingir estes níveis de formação ficarão de fora de uma economia onde o sucesso é medido pela produtividade, pela capacidade de inovação e pela criação de valor estratégico (...). A capacidade de criar valor a partir do conhecimento é essencialmente intangível e esta é a fonte de vantagem competitiva na sociedade atual. (KIM; MAUBORGNE, 1998 s/PP)

Figura 1.

DESAFIOS PARA O PROFESSORADO NA SOCIEDADE DO CONHECIMENTO 


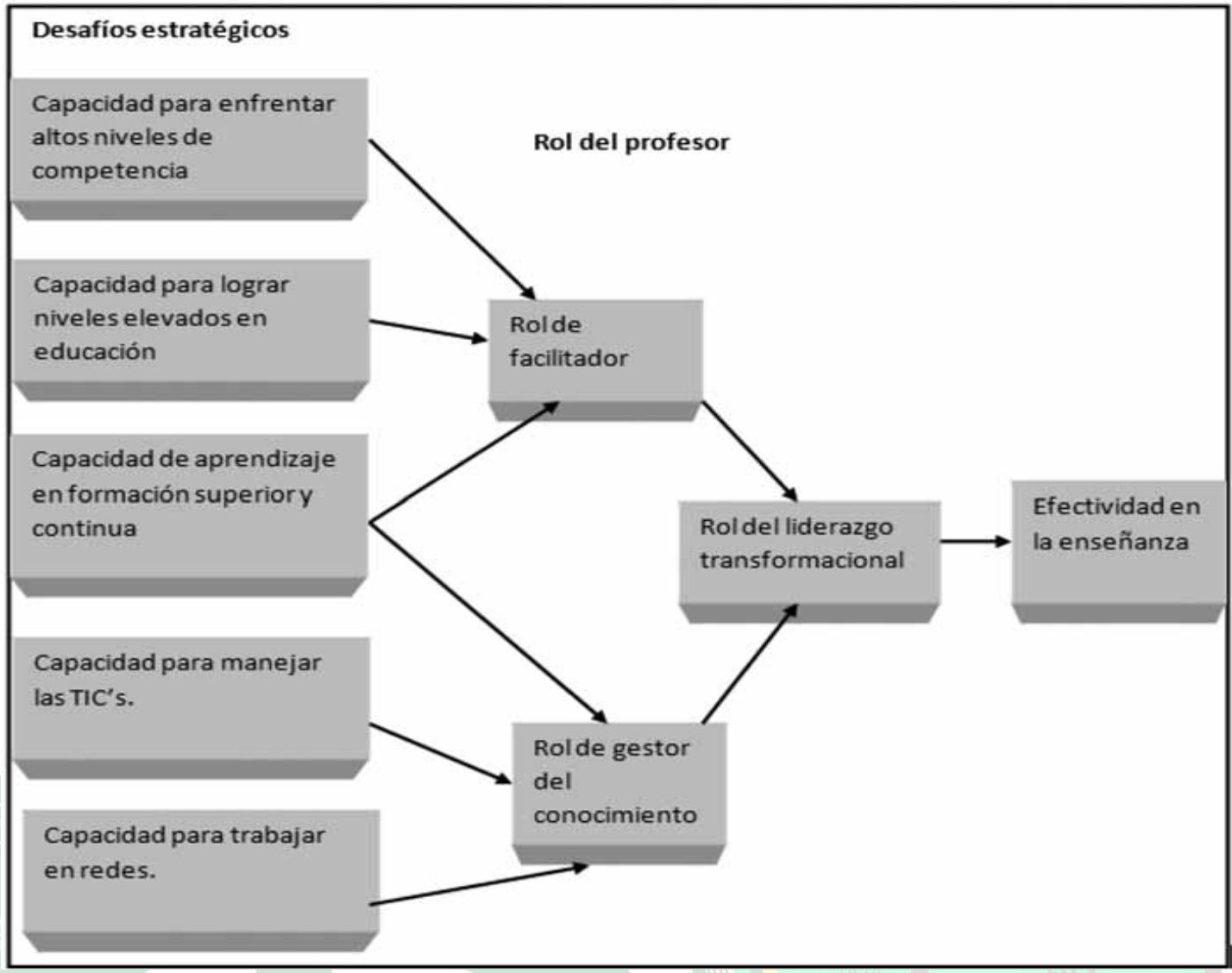

Figura 1 - Relação entre as demandas da sociedade do conhecimento para os estudantes e o papel do professorado. Fonte: Rejas; 2012

Esta complexa tarefa de assumir diversos papéis tais como facilitador, gestor de conhecimentos e líder transformacional, envolve a existência de uma série de conflitos particulares tais como: sentimento de inadequação e de preparo insatisfatório para esta mudança paradigmática no ensino e aprendizagem; disparidades entre a filosofia do ensino nesta modalidade de educação e a filosofia de vida própria em que o professor se insere e encontra-se ajustado ; ausência de apoio dos gestores de educacionais para desempenho adequado de suas tarefas e muitas outras não ditas.

Acresce-se aos adventos da educação na sociedade do conhecimento, na qual se inaugurou uma nova era em termos de inovadoras modalidades de construção de conhecimentos diversos, o imprescindível uso de Tecnologias de Informação e Comunicação (TIC) nas práticas docentes.

Vargas e Araújo (2020) quando se propõem a repensar sobre as Tecnologias de Informação e Comunicação (TIC) como ferramentas cognitivas de aprendizagem, mediadoras de conhecimento, a partir das quais os envolvidos possam adquirir competências e habilidades de perceber criticamente e influir ativamente na tomada de 
decisões, na possibilidade de análise, de produção e de invenção de uma nova sociedade e de novos conhecimentos (e pesquisas) ressaltam que:

\begin{abstract}
"os pesquisadores e educadores começam a se movimentar em busca de um novo horizonte da educação, que longe de um plano horizontal, mas sim, que se faz vertical e transversal. Por isso, abaixo, a outra categoria criada e evidenciada por meio da análise, diz respeito exatamente à necessidade de formação continuada para professores em exercício na profissão sobre o envolvimento de TIC nos processos de ensino e aprendizagem como ferramenta cognitiva pedagógica." (VARGAS; ARAÚJO, 2020, p 249 , grifo nosso)
\end{abstract}

O desenvolvimento de um trabalho eficiente executado pelos professores do século XXI não é isento de tensões diversas, pois deixar para trás o paradigma da sociedade anteriormente denominada como industrial e passar para a complexa sociedade atual requer rápidas e profundas mudanças tanto em sua pratica profissional como no seu modo de perceber o ato educativo e sua relação com seus educandos, pois tal papel inovador devem o levar a se tornar um professor reflexivo, dialógico e investigador.

Para Tardif (2002) citado in Pesce e André (2012) a prática reflexiva pode ajudar o professor a responder às situações incertas e flutuantes, dando condições de criar soluções e novos modos de agir no mundo. Todavia, a reflexão por si significa pouco, o importante é sobre o que refletir e como ocorre esse processo.

Esta nova atitude instigadora na qual o professor assume o papel de investigador em sua práxis vai demandar ao mesmo tempo no seu cotidiano um acréscimo ao seu "fazer", ou seja, um mais intenso compromisso com estudos constantes e uma permanente conexão com as inovações que ocorrem em sua área de conhecimento, pois não se pesquisa aquilo que já se sabe.

Lüdke (2001, p. 77-96) por sua vez tem sido defensora da formação do professor pesquisador, vendo na formação inicial a oportunidade de apropriação de um recurso que irá possibilitar que o professor possa questionar sua prática e o contexto no qual ela está inserida; portanto, a pesquisa representa "um recurso de desenvolvimento profissional" (p. 51). Nessa perspectiva, o professor será autor de seu trabalho, fazendo opções teóricas, metodológicas e políticas e sendo propositor de mudanças. Ainda em seus estudos para Lüdke (2006, p. 27-54), a prática da pesquisa dá mais recurso ao professor para questionar sua prática, levando-o a uma profissionalidade autônoma e responsável. 
A pesquisadora realça ser necessário que o futuro professor tenha acesso à formação e à prática da pesquisa. A formação inicial representa o lócus fundamental para que o profissional possa desenvolver uma postura investigativa. Ao formar-se (entender-se) professor pesquisador, seu pensamento e sua prática serão constitutivos desse saber.

Souza e Silva (2020, p. 326) enfocam a importância da prática da observação na formação inicial docente quando afirmam que:

\footnotetext{
"para que haja um aprimoramento da prática docente e uma aquisição de novos conhecimentos voltados para aprendizagem significativa (...) durante a formação docente, é necessário que os professores sejam instigados a refletir sobre as suas ações, buscando melhorias constantes para a qualificação da prática pedagógica." (SOUZA; SILVA, 2020, p. 326)
}

Historicamente o entendimento do significado de um professor como alguém que também simultaneamente se configura como um investigador tornando-se assim um "professor- pesquisador" em sua área de conhecimento se insurge por volta da década de sessenta. Esse movimento docente teve como intuito a promoção de mudanças pedagógicas e, por conseguinte no "fazer" do docente que foi sendo delineado progressivamente de forma distinta do que se assumia anteriormente.

Nóvoa (2001) destaca que, atualmente, falar em professor como pesquisador nos remete ao professor reflexivo, à pesquisa-ação, à pesquisa sobre a própria prática, entre outros. Tal fato leva a considerar que as diferentes denominações que caracterizam o professor pesquisador assentam-se sob o mesmo paradigma, o do professor reflexivo cujo escopo está em formar um professor que pensa e que reflete sobre sua própria prática, elaborando estratégias em cima dessa prática, assumindo assim sua realidade escolar como um objeto de pesquisa, de reflexão e de análise.

Diante das mudanças paradigmáticas mencionadas surgem então inquietações relacionadas às novas competências pedagógicas que se fazem necessárias para melhorar o desempenho do professor neste novo cenário educacional em constante transformação. Esta resposta evidentemente não é simples e muito menos direta.

Contudo, ressalta-se aqui uma provocação pertinente para aprofundamento dessa reflexão apoiados em Monereo (2010). Segundo o autor: 
durante o seu exercício profissional. Problemas com caráter emergente, ou seja, aqueles que, através da realização de certa análise prospectiva, se pode prever que terão uma presença cada vez mais evidente na sala de aula e uma influência progressivamente maior nos processos de ensino e aprendizagem (...). Mas quais são estes problemas? Mais uma vez a resposta a esta questão encontra um primeiro enigma: é difícil e fazer generalizações." (MONEREO, $2010, \mathrm{n} / \mathrm{p})$

Depreende-se que então que se faz imprescindível gerar espaços de formação pedagogicamente diferenciados e inovadores, que valorizem as investigações por parte dos professores em sua práxis cotidiana, a fim de criar uma formação com consequente perfil docente de alto nível que atenda aos diversos pré-requisitos que se impõem a esse segmento de profissionais e que garanta uma formação de alta qualidade e envergadura diante das crescentes demandas oriundas da sociedade do conhecimento.

Quadro 3 - Propostas de competências profissionais docentes.

\begin{tabular}{|c|c|}
\hline Competência cognitiva & Competência metodológica \\
\hline $\begin{array}{l}\text { Corresponde à capacidade do professor de } \\
\text { aproximar o aluno do conhecimento por } \\
\text { meio de um discurso pedagógico que } \\
\text { busca a inclusão em sala de aula. Baseia- } \\
\text { se no conhecimento pedagógico e sua } \\
\text { aplicação na resolução de problemas de } \\
\text { sala de aula. }\end{array}$ & $\begin{array}{l}\text { Está enquadrada em dois componentes: na } \\
\text { aproximação dos saberes específicos do } \\
\text { professor à realidade de cada aluno e no } \\
\text { fortalecimento da reflexão no processo } \\
\text { ensino-aprendizagem; isso torna } \\
\text { conhecimento pedagógico aplicável em } \\
\text { uma situação prática. }\end{array}$ \\
\hline Competência social & Competência pessoal \\
\hline $\begin{array}{l}\text { O professor reconhece seu contexto e } \\
\text { passa a fazer parte da comunidade } \\
\text { acadêmica, entendendo que ele é mais um } \\
\text { sujeito no processo acadêmico que } \\
\text { contribui para o alcance de um objetivo } \\
\text { educacional comum. }\end{array}$ & $\begin{array}{l}\text { Está associada ao profissionalismo e ao } \\
\text { desempenho ético com todos os } \\
\text { integrantes da comunidade acadêmica. O } \\
\text { professor atua com equidade e é } \\
\text { responsável por seus atos, respeitando os } \\
\text { limites das relações. }\end{array}$ \\
\hline
\end{tabular}

Fonte: Macías, Díaz e Soto, 2016

Demo (2011) quando se reporta a pesquisa como princípio científico e educativo assinala que a mesma se constitui em um elemento que integra de todo processo emancipatório. E, conforme assegura o autor, é nesse processo de emancipação que:

[...] se constrói o sujeito histórico autossuficiente, crítico e autocrítico, participante, capaz de reagir contra a situação de objeto e de não cultivar os outros como objeto [...] pesquisa como diálogo é processo cotidiano, integrante do ritmo da vida, produto e motivo de interesses sociais em confronto, base da aprendizagem que não se restrinja a mera reprodução; na 
acepção mais simples, pode significar conhecer, saber, informar- -se para sobreviver, para enfrentar a vida de modo consciente (DEMO, 2011, p. 4243).

Cumpre-se assinalar que este "novo" professor pesquisador reflexivo e crítico se encontra ainda inserido no imaginário social como dois profissionais diferentes, ou seja, um que apenas ensina e reproduz conhecimentos e outro que inova com suas pesquisas. Tal estereótipo precisa ser banido dos ambientes educacionais e sociais, pois o binômio ensino-pesquisa se tornou inseparável na Sociedade do Conhecimento.

\section{METODOLOGIA}

Trata-se de uma pesquisa qualitativa com caráter de revisão de literatura narrativa que versa sobre a análise da temática escolhida e análise de produções cientificas sobre as fontes de informações selecionadas.

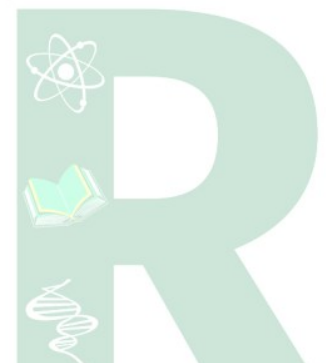

“A pesquisa qualitativa é definida como aquela que privilegia a análise de microprocessos, através do estudo das ações sociais individuais e grupais, realizando um exame intensivo dos dados, e caracterizado pela heterodoxia no momento da análise. Enfatiza-se a necessidade do exercício da intuição e da imaginação (...) num tipo de trabalho artesanal, visto não só como condição para o aprofundamento da análise, mas também - o que é muito importante - para a liberdade do intelectual.” (MARTINS, 2004, n/p)

Procedeu-se uma revisão do tipo narrativa, construídas com publicações amplas, apropriadas para descrever e discutir o desenvolvimento ou o "estado da arte" do assunto estudado, sob ponto de vista teórico ou contextual. "As revisões narrativas não informam as fontes de informação utilizadas, a metodologia para busca das referências, nem os critérios utilizados na avaliação e seleção dos trabalhos" (BERNARDO; et al.,2004, p. 1-9)

Contudo, cabe ainda corroborando com os autores supracitados os pressupostos de VARGAS E CALVO (1987; p 73-75), quando tais autores definem assim o significado do estado da arte:

\footnotetext{
"Um estudo analítico do conhecimento acumulado que faz parte da investigação documental, que se baseia na análise de documentos escritos, (esclarece-se a utilização feita pelos autores de duas modalidades de produções investigativas que foram os periódicos científicos e livros tendo como critério de escolha as palavras chaves descritas não se levando em consideração recortes temporais nessa modalidade de revisão).Visa inventariar e sistematizar a produção numa área de conhecimento, um exercício que não deve ser deixado sozinho no inventário, mas que deve transcender ainda mais, porque permite fazer uma reflexão aprofundada sobre
} 
as tendências e lacunas numa área específica (VARGAS E CALVO , 1987; $\mathrm{p} 73$ )

Diante do exposto acima, é plausível que a expressão estado da arte inicia um original campo de investigação (...) e como resultado, pode-se falar da investigação sobre a investigação. (Calvo (1992) citado por PATIÑO 2016; n/p).

Permite-se assim então enfatizar que a forma de investigação acima referida é caracterizada pela procura de várias fontes documentais que expandem a informação em torno do estado do conhecimento de um determinado assunto aprovado pela comunidade acadêmica.

O estado de arte tem por objetivo fazer uma leitura dos resultados alcançados nos processos sistemáticos de conhecimentos prévios, ou seja, a investigação documental é o ponto de partida para fundamentar outras propostas já existentes, mas com algo considerado moderno. Contudo, esse "novo" está atrelado na intencionalidade do investigador (Riano 1999; n/p).

Bojacá Acosta $(2004 ; \mathrm{n} / \mathrm{p})$ também indica (...) sete pretensões do estado da arte, incluindo delimitação e caracterização do campo, detecção e estudo relevante e recorrente, contextualizar a investigação no seu processo histórico, fazer um balanço de informação, para finalmente localizá-lo e relacioná-lo com outros dados.

Outra tendência encontrada nas definições é aquela em que se afirma que o estado da arte procura recuperar para transcender reflexivamente, seu principal interesse é alcançar a compreensão,e isto se baseia nas suas fases iniciais em inventários e análise bibliométrica.

Quadro 4- ¿Qué es el estado del arte? 


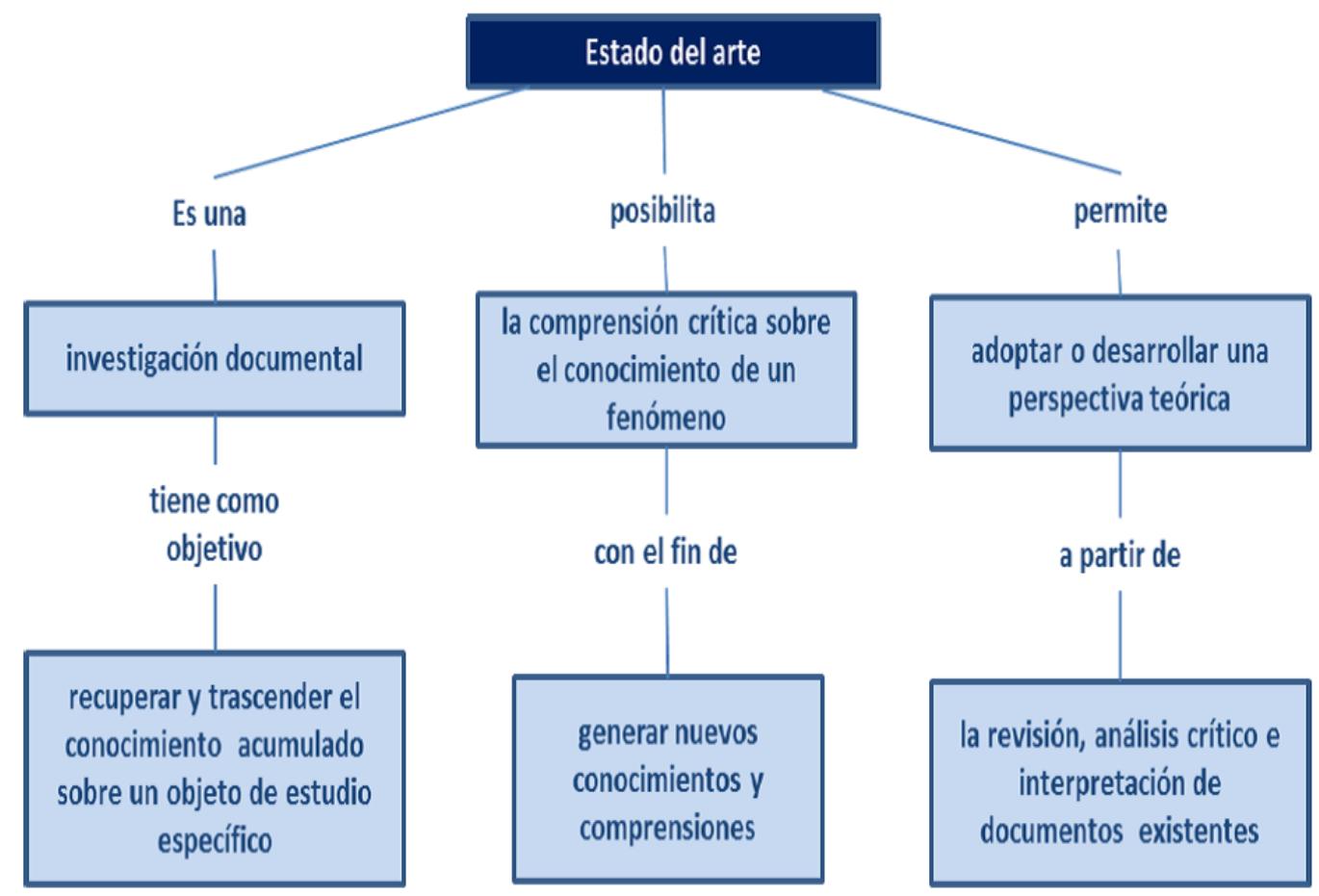

Fonte: Normas American Psychological Association(APA).

\section{DISCUSSÕES E RESULTADOS}

$\mathrm{Na}$ conjuntura da globalização o professor necessita de habilidades e competências diversificadas para viabilizar uma postura com cerne na pesquisa no processo ensino aprendizagem junto a seus alunos e para isto se faz necessário e imprescindível o suporte técnico para o uso de TIC no apoio ao ato educativo inserindose aí o estímulo, suporte constante e capacitação adequada para ensino-pesquisa junto aos educandos.

Ressalta-se que no cotidiano o uso da TIC torna a intercessão aluno e professor, mais fascinante, se forem utilizadas com um desenho contextualizado ao que se deseja apresentar e discutir em sala de aula e em pesquisas diversas fora do restrito espaço escolar.

As funcionalidades e ferramentas informacionais uma vez disponíveis tanto aos educandos como aos educadores promovem a inserção de assuntos mais complexos em que a participação do aluno em pesquisas pode ser gerada e incentivada.

Contudo, é preciso assinalar que o movimento do uso das TIC na educação em nosso país ainda se encontra em um estágio muito rudimentar. Existem lacunas 
significativas no tocante a capacitação docente/ discente gerando inseguranças e resistências ao seu uso voltado ao ensino.

Outro registro relevante diz respeito à fragilidade de políticas de acesso as TIC. Apontam-se aqui políticas incipientes no tocante ao número de computadores por aluno e na distribuição que estes apresentam nas escolas do país. Ressalta-se ainda que em relação à necessidade de fortalecimento de políticas públicas voltadas para o fortalecimento das TIC, inúmeros problemas que ficam a margem da autonomia docente tais como: A necessidade de reorientação dos programas de implantação dos equipamentos nas escolas assim como a sua constante manutenção, atualização e adaptação voltados para o acesso a serviços de alta velocidade, condição pedagógica adequada para o uso de programas e jogos, adequação da relação de um computador para cada aluno e para cada professor.

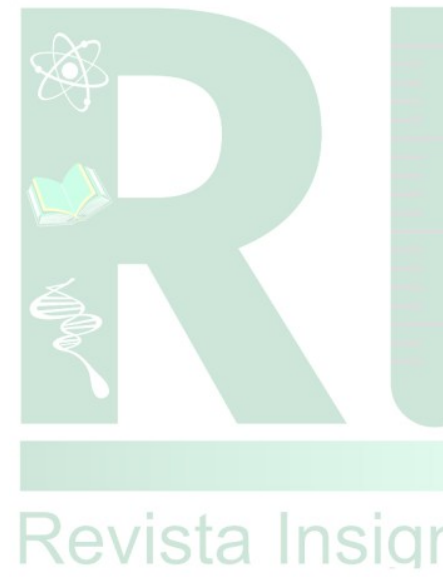

"Enquanto a formação inicial dos docentes não for capaz de incorporar o uso pedagógico das TIC - e as habilidades e destrezas em seu manejo, para gerações "imigrantes digitais" ou vítimas do hiato digital - sua mobilização para o ensino/aprendizagem nas escolas será sempre um "enxerto" de algo estranho ao processo e feito de fora para dentro. Assim sendo, a formação de docentes para o uso das TIC no ensino coloca três linhas de questões. A primeira consiste em saber em quê e como capacitar os docentes em exercício para o uso das TIC em atividades diárias na escola. A segunda é em que estágio da formação inicial, o quê e como capacitar os futuros docentes para uma utilização adequada da tecnologia? E, finalmente, como despertar nos docentes em exercício e nos futuros professores a consciência de que atualizações de conteúdo específico e nas novas tecnologias são indispensáveis para o processo de seu desenvolvimento profissional?" (BASTOS, 2020, p33)

Considera-se também que se faça primordial o genuíno interesse pelo fortalecimento de políticas públicas de acesso ao mundo digital no cotidiano retirando-o apenas da formulação e registros institucionalizados e colocando-as em prática.

O Plano Nacional de Educação 2014-2024 (PNE) por se tratar de uma política nacional, estratégica e de grande amplitude que aborda todas as etapas da Educação Básica e todos os aspectos da Educação Superior, propõe caminhos abrangentes para o uso das TIC e oferece, portanto, uma ampla gama de possibilidades para integrá-las ao currículo. (MONTEIRO; SILVA, 2016, p.8)

Acrescido a este contexto anteriormente exposto, entende-se que a publicação [de pesquisas] on-line possui uma capacidade de circulação e difusão incomparavelmente mais poderosa do que a dos materiais impressos, pois independe de impressão e de distribuição física. 


\section{CONSIDERAÇÕES FINAIS}

Sendo assim, pode-se afirmar a partir do que foi descrito, que a investigação como um princípio pedagógico está atualmente num momento de avanço de novos sistemas de acesso, intercâmbio de informação e de impactos gerados pela os avanços computacionais resultando assim em alterações positivas, mesmo não se desconhecendo todos os entraves ainda estão presentes para sua real implantação generalizada no contexto escolar.

Cabe ressaltar que apesar dos obstáculos presentes na inauguração desta conjuntura educacional pertinente aos novos tempos em que a sociedade do conhecimento impõe constantemente a educação respostas, os autores desse estudo acreditam que tal estratégia de produção de saberes configurada pela pesquisa.

Tal trajetória se constitui em um caminho avançado e fértil para formulação e abordagem de conhecimentos de caráter consistente e seguros relacionados as demandas em que a educação é instigada a se posicionar.

Este ato informacional conferido pelas pesquisas é mais que estritamente um simples retorno com respostas diante ao desconhecido, trata-se de uma atitude política assumida na atualidade pelos docentes e que contribui para embasamento de suas inquietações favorecidas pelo ato de ressignificação do antigo entendimento do ato de ensinar/pesquisar.

Hoje os professores pesquisadores vêm buscando ir muito mais além, desvendando e concebendo determinados conhecimentos acerca de diversos objetos de estudo. Contudo, cumpre assinalar que ainda necessitam de subsídios, não basta simplesmente a vontade de inovar. É preciso processos de capacitação constantes, políticas públicas eficazes e que essas sejam realmente colocadas em pratica para que os educadores da Sociedade do Conhecimento se sintam verdadeiramente aptos para enfrentarem os seus desafios cotidianos.

\section{REFERÊNCIAS BIBILIOGRÁFICAS}

APA. ¿Qué es el estado del arte? . Normas APA.26 mar.2017; n/p. Disponível em: https://normasapa.net/que-es-el-estado-del-arte/. Acesso em 12/10/2019.

BASTOS, M. I. O desenvolvimento de competências em "TIC para a educação" na formação de docentes na América Latina. Org.UNESCO.OREALC. Brasília. Abr. 2010. Disponível em: 
http://portaldoprofessor.mec.gov.br/storage/materiais/0000012844.pdf. Acesso em 22 set. 2020

BERNARDO, W.M.; NOBRE M.R.C.; Jatene F.B. A prática clínica baseada em evidências. Parte II: buscando as evidências em fontes de informação. Rev Assoc Med Bras, São Paulo, v.50, n.1, p. 1-9, 2004

BOJACÁ ACOSTA, J. E. XYZ Investigación Pedagógica Estado del Arte Semilleros. Bogotá: Universidad Santo Tomás de Aquino. (2004; n/p). In: Vargas; M.G. et al. El estado del arte: una metodología de investigación. Revista Colombiana de Ciências Sociales, 6(2), 423-442. Julio-diciembre. Medellín-Colombia.2015

BRAILOVSKY, D. Lo nuevo y lo tradicional en educación: una oposición engañosa. Revista Senderos Pedagógicos, n. 9, p. 161-176, jan/dez 2018. Disponível em: https://ojs.tdea.edu.co/index.php/senderos/article/view/623. Acesso em: 16 set. 2020.

DEMO, P. Pesquisa: princípio científico e educativo. 14. ed. São Paulo: Cortez, 2011.

FREIRE, Paulo. Pedagogia da autonomia: saberes necessários à prática educativa. 12. ed. São Paulo: Paz e Terra, 1999.

GUICHOT REINA, Virginia. Historia de la Educación: Reflexiones sobre su Objeto, Ubicación Epistemológica. Devenir Histórico y Tendencias Actuales. Rev Latino-Am. de Estudios Educativos, Universidad de Caldas Manizales, Colombia, v. 2, Núm. 1, p. 11- 51, jan. /jun. 2006.

KIM, W. C.; MAUBORGNE, R. Procedural justice, strategic decision making, and the knowledge economy. Strategic Management Journal. v. 19, n. 4, p. 323-338. 4 dez. 1998.

LIMA, L.; COSME, A. Desafios da formação de professores num contexto de mudança paradigmática na educação. Revista Intersaberes. ISSN: 1809-7286, p. 65-76, jan./abr. 2018. Disponível em:

https://www.researchgate.net/publication/325942370_Desafios_da_formacao_de_profes sores_num_contexto_de_mudanca_paradigmatica_na_educacao Acesso em: 23 jul. 2020

LÜDKE, M. A complexa relação entre o professor e a pesquisa. In: ANDRÉ, M. (Org.). O papel da pesquisa na formação e na prática dos professores. 5 . Ed. Campinas: Papirus, 2006. p. 27-54.

LÜDKE, M. O professor, seu saber e sua pesquisa. Educação \& Sociedade, Campinas: Unicamp, v. 22, n. 74, p. 77-96, abr. 2001.

MACIAS, M. A. A.; DIAZ, P. R.; SOTO, E. R. Propostas de competências profissionais para professores de programas de saúde. Rev. Faculdade. Medicina. [online], v 65, n 4, p.595-600 2017, ISSN 0120-0011. Disponível em:

http://dx.doi.org/10.15446/revfacmed.v65n4.58620. Acesso em: 20 ago. 2020

MARTINS, H. H. T. de S.. Metodologia qualitativa de pesquisa. Educ. Pesqui., São

Paulo, v. 30, n. 2, p. 289-300, ago. 2004. Disponível em:

http://www.scielo.br/scielo.php?script=sci_arttext\&pid=S1517-

$97022004000200007 \& \operatorname{lng}=\mathrm{en} \& n r m=$ iso. Acesso em 22 set. 2020.

MIZUKAMI, M. da G. N. Ensino: as abordagens do processo. 1. ed. São Paulo: EPU, 1986. 
MONEREO, C. La formación del profesorado: una pauta para el análisis e intervención a través de incidentes críticos. Rev. Ibero americana de Edu. Madrid, n. 52, p. 149178, 2010. Disponível em: https://www.encuentro-practico.com/pdf10/competenciaprofesional.pdf. Acesso em: 22 set. 2020

MONTEIRO, N. A.; SILVA M. da G. M. Da. O que dizem Políticas Públicas Educacionais sobre Tecnologias para a educação? 2016. 8 f. Investigação científica PUCSP, 2016. Disponível em:

http://www.abed.org.br/congresso2016/trabalhos/268.pdf. Acesso em 07 set. 2020.

MUÑOZ, R. F. Competencias profesionales del docente en la sociedad del siglo XXI. Organización y gestión educativa: Revista del Fórum Europeo de Administradores de la Educación, v. 11, n 1, p. 4-7, 2003, ISSN 1134-0312. Disponível em: https://dialnet.unirioja.es/servlet/articulo? Código=292590. Acesso em: 16 jun. 2020

NÓVOA, A. Os professores e a sua formação. Lisboa: Dom Quixote, 1992.

PATIÑO, R. G. El estado del arte en la investigación: ¿análisis de los conocimientos acumulados o indagación por nuevos sentidos? Revista Folios, núm. 44, juliodiciembre, 2016, pp. 165-179. Universidad Pedagógica Nacional. Bogotá, Colombia. Disponível em: https://www.redalyc.org/articulo.oa?id=345945922011.Acesso em $12 / 10 / 2020$

REJAS, P. L. Desafíos para el profesorado en la sociedad del conocimiento. Ingeniare. Rev. Chil. Ing., Arica, v. 20, n. 1, p. 136-144, abr. 2012. Disponível em: https://scielo.conicyt.cl/scielo.php?script=sci_arttext\&pid=S07183052012000100014\&lng=es\&nrm=iso. Acesso em: 16 jun. 2020.

RIANO, C. Producción de conocimiento y prácticas pedagógicas en educación para la convivência democrática desde el aula. Estado del Arte 1989-1999, Colégio Del Santo Angel, IDEP, Bogotá, 1999 n/p.

SOUZA, D. S. de; SILVA C. S. de S. da; BEDIN E. A relevância da observação na formação inicial docente com vistas no desenvolvimento da prática reflexiva. Revista Insignare Scientia, v. 3, n. 1. jan./abr. 2020 -ISSN 2595-4520 Disponível em: https://periodicos.uffs.edu.br/index.php/RIS/article/view/11250/7391. Acesso em 24 ago. 2020.

TARDIF, M. Saberes docentes e formação profissional. Petrópolis: Vozes, 2002 In PESCE, M. K. de. et al. Formação do professor pesquisador na perspectiva do professor formador. Rev. Form. Doc., Belo Horizonte, v. 04, n. 07, p. 39-50, jul./dez. 2012. Disponível em: https://pt.scribd.com/document/262494674/. Formacao-do-professorpesquisador-na-perspectiva-do-professor-formador. Acesso em: 06 set. 2020

VARGAS, R. S. de; ARAÚJO M. C. P. de. A construção de um novo paradigma educacional e sua relação com as tecnologias de informação e comunicação. Revista Insignare Scientia, v. 3, n.1. p. 235-256, 4 jun.2020. ISSN 2595-4520. Disponível em: https://periodicos.uffs.edu.br/index.php/RIS/article/view/11335/7384. Acesso em 24 ago. 2020

VARGAS, G. y CALVO, G. Seis modelos alternativos de investigación documental para el desarrollo de la práctica universitaria en educación... el caso del proyecto de extensión REDUC - Colombia en la Universidad Pedagógica Nacional. Revista Educación superior y desarrollo (1987;). In: Montoya; Nancy Piedad Molina. ¿Qué es el estado del arte? Ciencia y Tecnología para la salud Visual y Ocular No 5: 73-75 / Julio - Diciembre 2005. 